\title{
Shoulder injuries in soccer goalkeepers: review and development of a FIFA II+ shoulder injury prevention program
}

This article was published in the following Dove Press journal:

Open Access Journal of Sports Medicine

8 August 2016

Number of times this article has been viewed

\section{Benno Ejnisman' \\ Gisele Barbosa' \\ Carlos V Andreoli' \\ A de Castro Pochini' \\ Thiago Lobo ${ }^{2}$ \\ Rodrigo Zogaib ${ }^{2}$ \\ Moises Cohen' \\ Mario Bizzini ${ }^{3}$ \\ Jiri Dvorak ${ }^{3}$}

'Department of Orthopaedics,

Federal University of São Paulo,

${ }^{2}$ Sports Medicine Department, Santos

FC, São Paulo, Brazil; ${ }^{3}$ FIFA-Medical

Assessment and Research Centre,

Schulthess Clinic, Zurich, Switzerland
Correspondence: Benno Ejnisman Department of Orthopaedics, Federal University of São Paulo, Rua Estado de Israel 636, Cep 04022-002, São Paulo, SP, Brazil

Email bennoale@uol.com.br

\begin{abstract}
In the last years, shoulder injuries have represented an increasing health problem in soccer players. The goalkeepers are more exposed to shoulder disorders than other field players. Injury prevention exercises for upper limbs were cited in few studies involving throwing athletes, but we know that goalkeepers need a specific program. The purpose of this study is to describe the development of an adapted Fédération Internationale de Football Association (FIFA) 11+ program, namely the FIFA $11+$ shoulder, which targets the prevention of shoulder injuries in soccer goalkeepers. The FIFA $11+$ shoulder program is structured into three parts: general warming-up exercises, exercises to improve strength and balance of the shoulder, elbow, wrist, and finger muscles, and advanced exercises for core stability and muscle control. The exercises were selected based on recommendations from studies demonstrating high electromyographic activity.
\end{abstract}

Keywords: goalkeeper, shoulder, injury prevention, prevention program

\section{Introduction}

Soccer is the most popular sport worldwide, and participation in this sport can be associated with injuries. ${ }^{1}$ On average, an elite soccer player suffers from 1.5 to 7.6 injuries each 1,000 hours of training and 12 to 35 injuries each 1,000 hours of match. ${ }^{2,3}$ Kirkendall and Dvorak ${ }^{4}$ reported that the most common injured site was the lower limb $(67.7 \%)$, followed by the upper limb $(13.4 \%)$.

In the last years, shoulder injuries have represented an increasing health problem in soccer players. ${ }^{5}$ The modern soccer has been characterized by high speed, pressing, and marking. ${ }^{5}$ Many researchers have reported that goalkeepers are more exposed to upper limb lesion than other field soccer players. ${ }^{6,7}$

The percentage of shoulder damage that occurred during Athens 2004 and EURO 2004 was $3.8 \%$ and $4.4 \%$, respectively. ${ }^{8}$ Junge et $\mathrm{al}^{9}$ reported shoulder injuries between $2 \%$ and $13 \%$ during a 4 -year period (from 1998 to 2001) of international tournaments. The Fédération Internationale de Football Association (FIFA) collected data during Japan/Korea World Cup (2002) and Germany World Cup (2006) and reported higher percentages of upper extremity injury ( $4.6 \%$ and $8.2 \%$, respectively).

A third of shoulder injuries $(28 \%)$ sustained by professional soccer players are severe because of which participation in training and games is stopped for $\geq 28$ days. ${ }^{10}$ In a study of the UEFA European Championships, a total of 34 severe injuries were recorded, two of which were shoulder dislocation. ${ }^{11}$ Hart and Funk ${ }^{12}$ reported that a previous shoulder injury is a significant risk factor of more or repeated injuries than 
other soccer injuries in general. A majority of serious soccer shoulder injuries affect the glenoid labrum (84\%), and a smaller number are labral injuries with associated rotator cuff involvement (8\%). A minority ( $8 \%$ ) are isolated rotator cuff injuries.

\section{Prevention of soccer injuries: what about the upper extremity?}

Since the launch of FIFA $11+$, key publications have confirmed the preventive effects of the program and have evaluated its performance-improving effects in female as well as male amateur soccer players. ${ }^{13}$ Considerable reductions in the number of injured players, ranging between $30 \%$ and $70 \%$, have been observed among the teams that implemented the FIFA $11+$ program. ${ }^{14}$ This program has been mainly developed to prevent lower limb injuries - there is no specific program in the current literature to prevent upper limb lesions in soccer players.

Wilk et $\mathrm{al}^{15}$ developed the Advanced Throwers Ten Exercise Program. This program consists of exercises that restore muscle balance and symmetry in the overhead throwing athlete, which is necessary for the symptom-free return to sports after lesion. Injury prevention exercises for upper limbs are cited in few studies involving throwing athletes, ${ }^{16,17}$ but we know that soccer goalkeepers need a specific program.

McCall et al ${ }^{18}$ cited that the "five" most common injury risk-screening tests used by national soccer teams were the evaluation of flexibility (dynamic and static), physical fitness, joint mobility, balance/proprioception, and muscle endurance and peak strength. In the same study, the authors reported the exercise-based injury prevention strategies that were not specific for upper or lower limb injuries. The key preventive exercises used by national teams were similar to those reported for premier league clubs, albeit in a slightly different order of importance. ${ }^{18}$ For example, core, balance/ proprioception, and eccentric exercises also feature in the "Top five" of national teams' exercises. At the time of this review, there was no direct scientific evidence that core exercises can reduce injury risk in top-level soccer players, although evidence from other sports suggests some preventive capacity. ${ }^{19}$

Despite being supported for shoulder rehabilitation by some studies, eccentric exercise has a weak level of evidence in the scientific literature ${ }^{20}$ as it cannot be ascertained whether its beneficial effects on injury are specifically from the eccentric component. ${ }^{21,22}$ Finally, while flexibility is an important exercise for practitioners, two systematic reviews ${ }^{23,24}$ have shown that there is no conclusive evidence to support stretching to prevent injuries. Both reviews, however, also highlight that there is no sufficient reason to discontinue flexibility exercises in the training program.

The aim of this paper is to describe the development of an adapted FIFA $11+$ program, namely the FIFA $11+$ shoulder (FIFA $11+\mathrm{S})$, which targets the prevention of shoulder injuries in soccer goalkeepers.

\section{Development of the FIFA I I+S program}

The FIFA $11+$ S program is structured into sections according to the FIFA 11+ program already successfully used to prevent lesions. ${ }^{25}$ The exercises were selected based on recommendations from studies demonstrating high electromyographic activity, ${ }^{26-32}$ including additional exercises to provide variation and progression.

The program was developed by an international group of experts, including orthopedics expert in shoulder lesions, physiotherapists with experience in soccer lesion, and specialists in sports rehabilitation. For all the exercises, correct performance is of great importance. Therefore, the coach should supervise the program and correct the players if necessary.

The program consists of three parts: general warming-up exercises (part I), exercises to develop strength and balance of the shoulder, elbow, wrist, and finger muscles (part II), and advanced exercises for core stability and muscle control (part III). The FIFA $11+\mathrm{S}$ takes $\sim 20-25$ minutes to complete and replaces the usual warm-up before training (Figure 1). All exercises focus on core stability, neuromuscular control, eccentric rotator strength, and agility.

These exercises should be performed three times per week and should be added to the training taken by the soccer goalkeeper. Part I exercises should be done for 7 minutes as a general warm-up. Part II exercises should be performed for 9-10 minutes in a low-resistance (light tubing strength or 2-3 kg), high-repetition format (three sets of 15-20 repetitions), in order to improve strength and local muscular endurance. ${ }^{33}$ Exercise should be changed according to the tolerance of the athlete (to A instead of B and C exercises, Figure 1). In part III, the athlete must do the exercises at high velocities with five or six sets of 15-20 repetitions not exceeding 9-10 minutes; these exercises are performed to increase local muscular endurance. ${ }^{33}$

The emphasis is given to the strengthening of some muscle groups such as the shoulder rotator cuff. The external and internal concentric rotation power balance ratio must be maintained between 0.6 and $0.8 .^{34}$ Regarding athletes with 
instability, Ellenbecker and Davies ${ }^{35}$ suggested as a preventive measure an increase of $10 \%$ in the normal strength relation (from $66 \%$ to $76 \%$ ), altering the rotator's relation from $2 / 3$ to $3 / 4$. Internal rotator is an important component of the throwing movement; on the other hand, the antagonist (external rotator) must be strong enough to decelerate the throwing movement and to stop the ball when grabbing it.
Other important muscles that should be focused on are the anterior serratus and lower and medium trapezium to prevent the scapular dyskinesia. The power of these muscles and superior trapezium keeps the correct scapulohumeral rhythm. $.22,36-39$

Open kinetic chain exercises with ball-throwing movements are included, in addition to closed kinetic chain

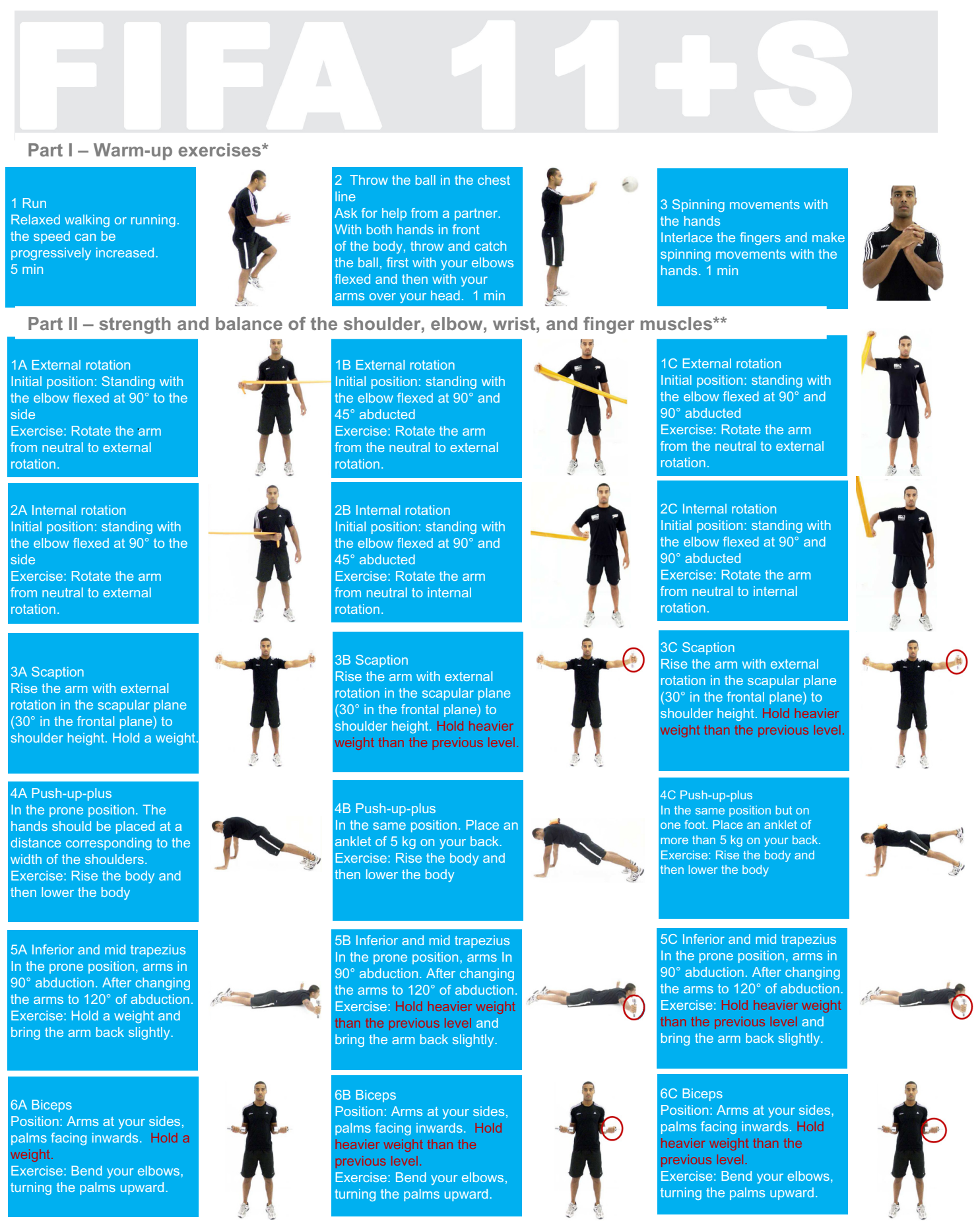

Figure I (Continued) 

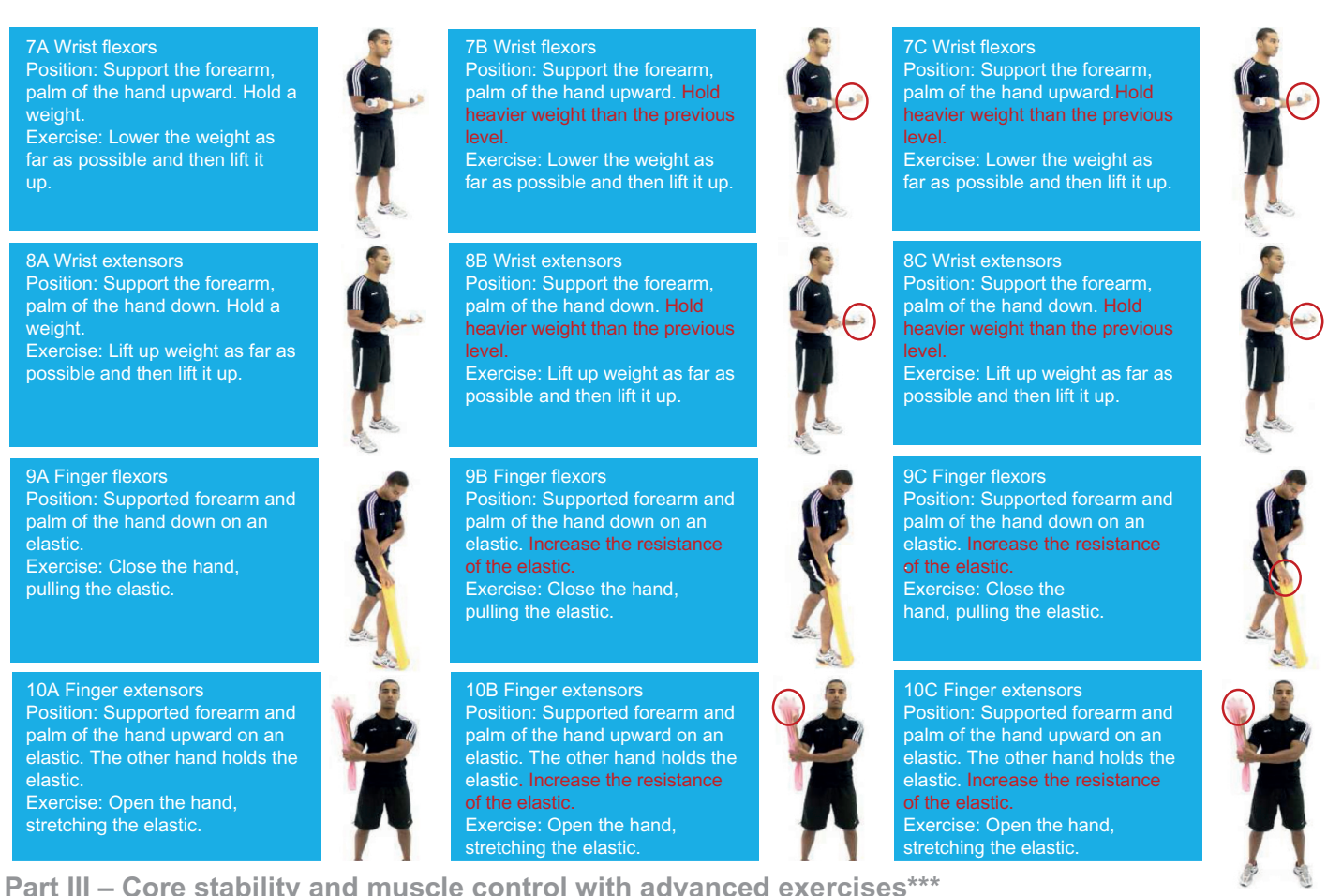

Part III - Core stability and muscle control with advanced exercises ${ }^{* * *}$
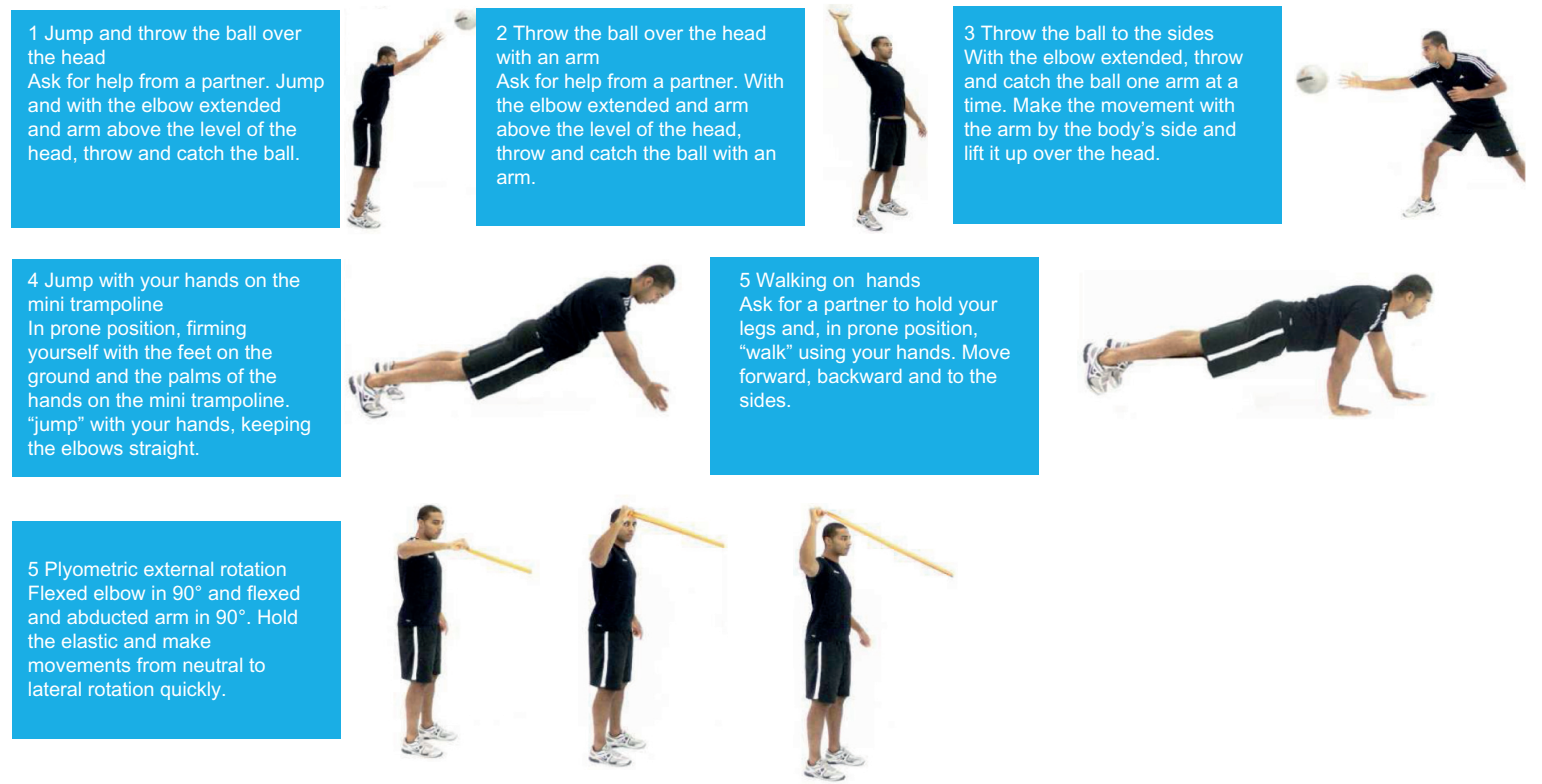

Figure I The FIFA II+ shoulder injury prevention program.

Notes: *Part I should be performed for 7 minutes. **Part II should be performed in 9-10 minutes at 3 sets of 15 repetitions. Exercises should be changed according to the tolerance of the athlete (to A for B and C exercises). ***Part III, the athlete must do the exercises at high velocities with 5 or 6 sets of 15 to 20 repetitions, not exceeding 9-10 minutes.

exercises that simulate falls and movements on the ground. In both cases, the CORE activation is needed to maintain the correct muscular activation sequence, and transfer and dissipate energy in the kinetic chain. ${ }^{29,40}$

The diagonal exercises are used to strengthen the muscles. The diagonal D1 in the flexor pattern (acceleration) and extension (deceleration) activates the rotator cuff, scapular waist, and deltoid muscles, which is important to improve the co-activation of the intra-articular power couples. ${ }^{37,41}$

The sensory-motor training is an important part of the program. The lack of shoulder stability increases the need of the sensory-motor system for neuromuscular control. The feed forward and feedback mechanisms are considered 
as critical points of the kinetic chain, making their training extremely important for the prevention of lesions. ${ }^{42}$

Plyometric training is also included, which facilitates the increase of excitability of the neural system and the reactive capacity of the neuromuscular system of healthy athletes' shoulders. This training includes the eccentric movement that produces elastic energy and transforms this accumulated energy into kinetic energy which is transferred to the concentric phase using the shortening-strengthening cycle. $^{30-32,43}$

\section{Conclusion and future perspectives}

We would like to recommend scientists and clinicians to also consider researching upper extremity injury in soccer goalkeepers. Considering favorable results from the previously published research on FIFA 11+ with soccer athletes, we hypothesize the following benefits of FIFA $11+\mathrm{S}$ : fewer injuries, fewer costs, and better performance by soccer goalkeepers.

One of the strengths of this study is the type of athletes involved, who have not been discussed in the literature, considering the difficulties in obtaining a program specific for goalkeepers. The lack of results about the use of this preventive program is the limitation of this paper.

Future research should investigate the effects of FIFA $11+\mathrm{S}$ to prevent injuries of the upper limbs and improve performance of the soccer goalkeepers.

\section{Disclosure}

The authors report no conflicts of interest in this work.

\section{References}

1. Longo UG, Loppini M, Cavagnino R, Maffulli N, Denaro V. Musculoskeletal problems in soccer players: current concepts. Clin Cases Miner Bone Metab. 2012;9(2):107-111.

2. Dvorak J, Junge A, Chomiak J, et al. Risk factor analysis for injuries in football players. Possibilities for a prevention program. Am J Sports Med. 2000;28(5 Suppl):S69-S74.

3. Hägglund M, Waldén M, Ekstrand J. Exposure and injury risk in Swedish elite football: a comparison between seasons 1982 and 2001. Scand J Med Sci Sports. 2003;13(6):364-370.

4. Kirkendall DT, Dvorak J. Effective injury prevention in soccer. Phys Sports Med. 2010;38(1):147-157.

5. Longo UG, Loppini M, Berton A, Martinelli N, Maffulli N, Denaro V. Shoulder injuries in soccer players. Clin Cases Miner Bone Metab. 2012;9(3):138-141.

6. Terra BB, Ejnisman B, Figueiredo EA, et al. Arthroscopic treatment of glenohumeral instability in soccer goalkeepers. Int J Sports Med. 2013;34(6):473-476.

7. Cohen M, Abdalla RJ, Ejnisman B, Amaro JT. Lesões ortopédicas no futebol [Orthopedic injuries in football]. Rev Bras Ortop. 1997;32: 940-944. Portuguese.

8. Junge A, Langevoort G, Pipe A, et al. Injuries in team sport tournaments during the 2004 Olympic Games. Am J Sports Med. 2006; 34(4):565-576.
9. Junge A, Dvorak J, Graf-Baumann T, et al. Football injuries during FIFA tournaments and the Olympic Games, 1998-2001: development and implementation of an injury-reporting system. Am J Sports Med. 2004;32(1 Suppl):80S-89S.

10. Ekstrand J, Hagglund $M$, Walden M. Injury incidence and injury patterns in professional football: the UEFA injury study. Br J Sports Med. 2011;45(7):553-558.

11. Hagglund M, Walden M, Ekstrand J. UEFA injury study: an injury audit of European championships 2006-2008. Br J Sports Med. 2009;43(7):483-484.

12. Hart D, Funk L. Serious shoulder injuries in professional soccer: return to participation after surgery. Knee Surg Sports Traumatol Arthrosc. 2015;23(7):2123-2129.

13. Bizzini M, Dvorak J. FIFA 11+: an effective programme to prevent football injuries in various player groups worldwide-a narrative review. Br J Sports Med. 2015;49(9):577-579.

14. Barengo NC, Meneses-Echávez JF, Ramírez-Vélez R, Cohen DD, Tovar G, Bautista JE. The impact of the FIFA $11+$ training program on injury prevention in football players: a systematic review. Int $J$ Environ Res Public Health. 2014;11(11):11986-12000.

15. Wilk KE, Yenchak AJ, Arrigo CA, Andrews JR. The Advanced Throwers Ten Exercise Program: a new exercise series for enhanced dynamic shoulder control in the overhead throwing athlete. Phys Sports Med. 2011;39(4):90-97.

16. Reinold MM, Gill TJ, Wilk KE, Andrews JR. Current concepts in the evaluation and treatment of the shoulder in overhead throwing athletes, part 2: injury prevention and treatment. Sports Health. 2010;2(2):101-115.

17. NiederbrachtY, Shim AL, Sloniger MA, Paternostro-Bayles M, Short TH. Effects of a shoulder injury prevention strength training program on eccentric external rotator muscle strength and glenohumeral joint imbalance in female overhead activity athletes. $J$ Strength Cond Res. 2008;22(1):140-145

18. McCall A, Davison M, Andersen TE, et al. Injury prevention strategies at the FIFA 2014 World Cup: perceptions and practices of the physicians from the 32 participating national teams. Br J Sports Med. 2015;49(9):603-608.

19. McMaster WC, Long SC, Caiozzo VJ. Shoulder torque changes in the swimming athlete. Am J Sports Med. 1992;20(3):323-327.

20. Maffulli N, Longo UG, Spiezia F, et al. Aetiology and prevention of injuries in elite young athletes. Med Sport Sci. 2011;56:187-200.

21. Ciullo JV, Stevens GG. The prevention and treatment of injuries to the shoulder in swimming. Sports Med. 1989;7(3):182-204.

22. Van der Hoeven H, Kibler WB. Shoulder injuries in tennis players. Br J Sports Med. 2006;40(5):435-440.

23. Ellenbecker TS. Rehabilitation of shoulder and elbow injuries in tennis players. Clin Sports Med. 1995;14(1):87-110.

24. McCann PD, Bigliani LU. Shoulder pain in tennis players. Sports Med. 1994;17(1):53-64.

25. Fifa 11+ a complete warm-up programme. Available from: http://f-marc. com $/ 11 \mathrm{plus} /$ manual $/$. Accessed December 21, 2015.

26. Moseley JB Jr, Jobe FW, Pink M, Perry J, Tibone J. EMG analysis of the scapular muscles during a shoulder rehabilitation program. Am J Sports Med. 199;20(2):128-134.

27. Cricchio M, Frazer C. Scapulothoracic and scapulohumeral exercises: a narrative review of electromyographic studies. J Hand Ther. 2011; 24(4):322-333.

28. Tsuruike M, Ellenbecker TS. Serratus anterior and lower trapezius muscle activities during multi-joint isotonic scapular exercises and isometric contractions. J Athl Train. 2015;50(2):199-210.

29. Sciascia A, Kuschinsky N, Nitz AJ, Mair SD, Uhl TL. Electromyographical comparison of four common shoulder exercises in unstable and stable shoulders. Rehabil Res Pract. 2012;2012:783824.

30. Cools AM, Witvrouw EE, De Clercq GA, et al. Scapular muscle recruitment pattern: electromyographic response of the trapezius muscle to sudden shoulder movement before and after a fatiguing exercise. J Orthop Sports Phys Ther. 2002;32(5):221-229. 
31. Gaunt BW, McCluskey GM, Uhl TL. An eletromyographic evaluation of subdividing active-assistive shoulder elevation exercise. Sports Health. 2010;2(5):424-432.

32. Reinold MM, Escamilla RF, Wilk KE. Current concepts in the scientific and clinical rationale behind exercises for glenohumeral and scapulothoracic musculature. J Orthop Sports Phys Ther. 2009;39(2): 105-117.

33. Fleck S, Kraemer W. Designing Resistance Training Programs. Champaign, IL: Human Kinetics; 2004.

34. Kibler WB, Thomas SJ. Pathomechanics of the throwing shoulder. Sports Med Arthrosc. 2012;20(1):22-29.

35. Ellenbecker TS, Davies GJ. The application of isokinetics in testing and rehabilitation of the shoulder complex. J Athl Train. 2000; 35(3):338-350.

36. Kibler WB, Ludewig PM, McClure PW, Michener LA, Bak K, Sciascia AD. Clinical implications of scapular dyskinesis in shoulder injury: the 2013 consensus statement from the 'Scapular Summit'. Br J Sports Med. 2013;47(14):877-885.

37. Escalamilla RF, Barrentine SW, Fleisig GS, et al. Pitching biomechanics as a pitcher approaches muscular fatigue during a simulated baseball game. Am J Sports Med. 2007;35(1):23-33.
38. Cools AM, Dewitte V, Lanszweert F, et al. Rehabilitation of scapular muscle balance: which exercises to prescribe? Am J Sports Med. 2007;35(10):1744-1751.

39. Burkhart SS, Morgan CD, Kibler WB. The Disabled throwing shoulder: spectrum of pathology. Part 3: The SICK Scapula, scapula dyskinesis, the kinetic chain, and rehabilitation. Arthroscopy. 2003;19(6):641-661.

40. Kibler WB, Press J, Sciascia A. The role of core stability in athletic function. Sports Med. 2006;36(3):189-198.

41. Burkhart SS, Morgan CD, Kibler WB. The Disabled throwing shoulder: spectrum of pathology. Part 1: Pathoanatomy and biomechanics. Arthoscopy. 2003;19(4):404-420.

42. Tripp BL, Yochem EM, Uhl TL. Recovery of upper extremity sensorimotor system activity in baseball athletes after a throwing - fatigue protocol. J Athl Train. 2007;42(4):452-457.

43. Chmielewski TL, Myer GD, Kauffman D, Tillman SM. Plyometric exercise in the rehabilitation of athletes: physiological responses and clinical application. J Orthop Sports Phys Ther. 2006;36(5):308-319.
Open Access Journal of Sports Medicine

\section{Publish your work in this journal}

Open Access Journal of Sports Medicine is an international, peer-reviewed, open access journal publishing original research, reports, reviews and commentaries on all areas of sports medicine. The manuscript management system is completely online and includes a very quick and fair peer-review system.

\section{Dovepress}

Visit http://www.dovepress.com/testimonials.php to read real quotes from published authors. 